\title{
Aumento de fertilidade como eventual mecanismo de manutenção das altas freqüências de hemoglobinopatias no Brasil
}

\author{
Increased fertility as an eventual mechanism maintaining high frequencies of hemoglobinopathies in Brazil
}

\author{
Michelle Marcondes Mazzi ${ }^{1}$ \\ Rosa Chelminsky Teixeira ${ }^{2}$ \\ Luís Alberto Magna ${ }^{3}$ \\ Antonio Sérgio Ramalho ${ }^{3}$
}

\begin{abstract}
unitermos resumo
Hemoglobinopatias

Fertilidade diferencial

O aumento da fertilidade das heterozigotas é um dos mecanismos sugeridos na manutenção do polimorfismo balanceado das hemoglobinopatias em alguns países. No presente trabalho, estudamos

Polimorfismos balanceados a fertilidade de 68 portadoras do traço talassêmico $\beta$ (heterozigotas AT) e de 53 portadoras do traço falciforme (heterozigotas AS) casadas com indivíduos com hemoglobina normal. O número médio de filhos por heterozigotas AT e AS (2,7647 e 3,0755, respectivamente) não diferiu significativamente do observado entre suas irmãs com hemoglobina normal (2,3778 e 3, respectivamente). Além disso, também não foi observada diferença significativa, quanto à proporção de mulheres casadas sem filhos, entre as heterozigotas e as suas irmãs. Tais resultados não favorecem, portanto, a hipótese de que o aumento de fertilidade das heterozigotas seja um mecanismo de manutenção do polimorfismo da talassemia $\beta$ e da hemoglobina $S$ no Brasil.
\end{abstract}

\section{abstract}

Abstract Increased fertility of heterozygous women is one of the suggested processes maintaining balanced polymorphism of the hemoglobinopathies in some countries. In the present work we studied the fertility of $68 \beta$-thalassemia trait (heterozygous AT) and 53 sickle cell trait (heterozygous AS) women married with normal hemoglobin husbands. The average number of children per heterozygous AT and AS women

(2.7647 and 3.0755, respectively) did not differ significantly from those observed among their control sisters with normal hemoglobin (2.3778 and 3, respectively). In addition, it was not observed a significant difference between the proportion of married women without children between the heterozygous women and their control sisters. The results herein presented hence does not support the hypothesis of increased fertility of heterozygous women as being a homeostatic mechanism able to maintain the polymorphism of either $\beta$-thalassemia and hemoglobin S in Brazil.

\section{key words}

Hemoglobinopathies

Differential fertility

Balanced polymorphisms

\section{Introdução}

As hemoglobinopatias estão classificadas entre as alterações genéticas mais freqüentes nas populações humanas, afetando cerca de 250 milhões de pessoas em todo o mundo. Cerca de 4,5\% da população mundial manifestam, portanto, uma hemoglobinopatia (4).
Em decorrência da composição étnica das populações brasileiras, as hemoglobinopatias também são muito freqüentes em nosso país $(15,18)$, atingindo algumas delas, como a hemoglobina $S$ e a talassemia $\beta$, grande importância em nível de saúde pública. De fato, cerca
1. Mestre em Ciências Biomédicas pela Faculdade de Ciências Médicas da Universidade Estadual de Campinas (FCM/Unicamp). 2. Coordenadora do Núcleo de Cenética da Prefeitura Municipal de Araras, SP.

3. Professor titular do Departamento de Cenética Médica da FCM/Unicamp. 
de $6 \%$ a $10 \%$ dos negróides brasileiros são heterozigotos do gene da hemoglobina S, e cerca de $1 \%$ a $6 \%$ dos caucasóides do Sul e do Sudeste do Brasil são heterozigotos do gene da talassemia $\beta$, o que ocasiona uma incidência significativa de homozigotos portadores de anemias hemolíticas crônicas (16).

Um aspecto que sempre despertou o interesse dos epidemiologistas e dos geneticistas foi o de algumas hemoglobinopatias, como é o caso da hemoglobina $S$ e da talassemia $\beta$, atingirem freqüências extremamente elevadas em certas populações, a despeito do alto coeficiente seletivo dos genes que as determinam. De fato, salta à vista que a taxa de mutações ou de casamentos preferenciais seria incapaz de contrabalançar a eliminação dos genes dessas hemoglobinopatias, feita pela seleção praticamente total dos homozigotos antes da idade reprodutiva, que ocorria na maioria das populações, pelo menos até há bem pouco tempo (3). Em outras palavras, a gravidade da anemia falciforme (homozigotos SS) e da talassemia maior (homozigotos TT), até recentemente fatais na infância na falta de tratamento adequado, torna difícil explicar a manutenção do polimorfismo da hemoglobina $S$ e da talassemia $\beta$ por mutações recorrentes em determinadas populações. Assim sendo, é forçoso pensar em outros mecanismos homeostáticos mantendo o polimorfismo dessas hemoglobinopatias.

Haldane (10), verificando a semelhança das distribuições geográficas da talassemia $\beta$ e da malária causada pelo Plasmodium falciparum, sugeriu a hipótese de que os heterozigotos da talassemia $\beta$ teriam vantagem seletiva em relação aos normais, no que diz respeito a este tipo de malária. Assim sendo, os indivíduos com a talassemia $\beta$ homozigótica morreriam antes da idade reprodutiva em virtude da própria doença, enquanto os homozigotos normais seriam mais eliminados pela malária do que os heterozigotos, cuja freqüência aumentaria nas populações.

O mesmo raciocínio de Haldane em relação à malária e à talassemia foi empregado por Allison (1) para explicar o polimorfismo da hemoglobina S na África. Embora a hipótese da malária tenha recebido evidências desfavoráveis em algumas populações e favoráveis em outras, ela ganhou grande popularidade, passando a ser empregada como exemplo clássico de manutenção de polimorfismos por seleção a favor dos heterozigotos.

Vários estudos mais recentes sugerem, no entanto, a existência de mecanismos homeostáticos alternativos ou complementares à hipótese da malária, atuando na ma- nutenção do polimorfismo da hemoglobina $S$ e da talassemia $\beta$. Na opinião de Eaton (7), por exemplo, apesar de décadas de estudos epidemiológicos e especulações, o mecanismo de seleção favorável do gene da hemoglobina $S$ ainda é desconhecido. Este autor ressalta o fato de a mortalidade pela malária ser insuficiente para, por si só, explicar as altas freqüências de hemoglobina $S$ observadas em áreas endêmicas do Plasmodium falciparum. Além disso, apesar das evidências geográficas, os mecanismos de proteção dos talassêmicos heterozigotos contra o Plasmodium falciparum ainda não estão esclarecidos $(9,11$, $12,14,17)$.

De acordo com Flint et al. (8), dois aspectos parecem enfraquecer a hipótese da malária: em primeiro lugar, a malária e as hemoglobinopatias não são coincidentes em algumas regiões (como é o caso do Brasil) e, em segundo lugar, a hipótese da malária não explica facilmente por que nem sempre as áreas malarígenas do mundo possuem a mesma hemoglobinopatia ou a mesma associação de hemoglobinopatias. Ainda segundo esses autores, a hipótese da malária deve ser sempre considerada em combinação com outros fatores.

Segundo Lisa et al. (12), a teoria da malária seria plenamente confirmada se fosse constatada uma correlação positiva direta entre a freqüência de heterozigotos da talassemia $\beta$ e os níveis de incidência e mortalidade desta doença parasitária. Este, no entanto, não é o caso das povoações da Sardenha, nas quais a correlação entre os graus de morbidade da malária e a freqüência de heterozigotos da talassemia é fraca. Esta observação levou à hipótese de que a malária não seria o fator seletivo de uma mutação talassêmica autóctone na Sardenha, mas o fator de manutenção de uma mutação introduzida por fluxo gênico externo durante as conquistas fenícias e cartaginesas.

Pesquisando mecanismos alternativos ou complementares à malária para explicar a manutenção do polimorfismo da talassemia na Sardenha, Lisa et al. (12) aventaram a hipótese do aumento da fertilidade das talassêmicas heterozigotas. Para testá-la, eles realizaram um estudo indireto de fertilidade nesta ilha, utilizando dados demográficos de 1961, época em que a malária ainda era endêmica naquele local. Os autores analisaram os dados de 52 povoações sardas, classificadas de acordo com a freqüência alta ou baixa de heterozigotas da talassemia $\beta$. Os resultados obtidos apoiaram a hipótese de aumento da fertilidade média nos locais onde a freqüência de heterozigotas era alta. De fato, um número médio de filhos 
por mulher e uma baixa porcentagem de mulheres casadas sem filhos foram demonstrados nas povoações com alta freqüência de heterozigotas. Em tais locais, o número médio de filhos por mulher era $10 \%$ a $20 \%$ maior do que em áreas com baixa freqüência de heterozigotas da talassemia $\beta$.

Ao analisar, no entanto, o aumento da fertilidade média em locais com alta freqüência de heterozigotas e alta incidência de malária, dois aspectos devem ser considerados. Em primeiro lugar, a maior fertilidade pode ser realmente atribuída à maior quantidade de heterozigotas na população, as quais teriam, por razões genéticas desconhecidas, maior fertilidade. Em segundo lugar, a maior fertilidade também pode ser atribuída à maior quantidade de mulheres com imunidade à malária, adquirida já na infância e, conseqüentemente, com menor perda fetal por malária. De fato, o efeito de diferentes graus de malária sobre o comportamento reprodutivo das heterozigotas já havia sido demonstrado anteriormente por Zei et al. (22).

Outro aspecto a ser levado em consideração na hipótese de Lisa et al. (12) é o da média de filhos ter sido comparada entre populações de regiões distintas da Sardenha, nas quais os aspectos socioeconômicos e culturais (idade média das mulheres por ocasião do casamento, por exemplo) podem diferir. Realmente, sabe-se que as povoações com alta freqüência da talassemia $\beta$ situam-se em regiões baixas e pantanosas da Sardenha, onde a malária foi hiperendêmica. Já as povoações com baixa freqüência de talassemia situam-se, evidentemente, nas zonas montanhosas altas, com baixa incidência de malária (21).

O presente estudo teve por objetivo testar a hipótese da fertilidade diferencial das heterozigotas da talassemia $\beta$, por intermédio de um estudo direto de fertilidade, em área não-malarígena e com o uso de controles da mesma faixa etária, nível socioeconômico e cultural.

Como a hemoglobina $S$ é muito freqüente em nosso país, julgou-se oportuno testar simultaneamente a fertilidade das heterozigotas com o traço falciforme.

\section{Casuística e métodos}

O projeto deste trabalho foi previamente aprovado pelo Comitê de Ética em Pesquisa da Faculdade de Ciências Médicas da Universidade Estadual de Campinas (FCM/ Unicamp) (Parecer no 321/2000) e pela Comissão Nacional de Ética em Pesquisa do Ministério da Saúde (Parecer Conep no 143/2001).
A pesquisa foi realizada em Araras (SP), por estar situada em área não-malarígena e também pelo fato de esta cidade possuir, desde 1988, um Programa Comunitário de Hemoglobinopatias, com um cadastro bem organizado de famílias com a talassemia $\beta$ e com a hemoglobina $S$ (20). Os indivíduos participaram voluntariamente do programa e receberam, em caráter opcional, aconselhamento genético e, quando necessário, tratamento médico.

Com base nesse cadastro foram escolhidas, por ordem de registro, 68 portadoras assintomáticas do traço talassêmico $\beta$ (heterozigotas AT), casadas ou em parceria estável com indivíduos com hemoglobina normal (homozigotos $\mathrm{AA}$ ), tendo como controles 45 irmãs $\mathrm{AA}$ casadas com indivíduos igualmente AA. A idade das heterozigotas AT ( média = 40,132 anos e desvio-padrão = 12,707 anos) foi comparada com a das suas irmãs AA ( édia $=38,044$ anos e desvio-padrão $=14,552$ anos) pelo teste de Mann-Whitney, sem ter sido observada diferença significativa $(p=0,4868)$.

Da mesma forma, foram escolhidas seqüencialmente 53 portadoras assintomáticas do traço falciforme (heterozigotas AS), casadas ou em parceria estável com indivíduos com hemoglobina normal (homozigotos $A A$ ), tendo como controles 43 irmãs AA casadas com indivíduos igualmente AA. A idade das heterozigotas AS (média = 34,679 anos e desviopadrão $=9,715$ anos) foi comparada com a das suas irmãs AA (média $=31,837$ anos e desvio-padrão $=10,353$ anos) pelo teste de Mann-Whitney, sem ter sido observada diferença significativa $(p=0,1905)$. Não foram incluídas no estudo mulheres viúvas ou separadas, por não se conhecer o término da sua vida reprodutiva. Da mesma forma, não foram incluídas heterozigotas detectadas na triagem pré-natal, para não introduzir um viés no estudo de fertilidade.

Tanto nas heterozigotas quanto nas suas irmãs AA, verificou-se o número total de gestações a termo (filhos vivos, falecidos e natimortos). A análise de fertilidade foi realizada pela comparação das médias de filhos pelo teste não- paramétrico de Mann-Whitney, bem como pela comparação das proporções de mulheres com e sem filhos, entre heterozigotas e controles. Os abortamentos não foram considerados, por serem indicadores de infertilidade e por não serem relevantes para o presente estudo, podendo introduzir algum viés nos resultados $(5,6)$.

Com objetivo de avaliar a freqüência do uso de métodos anticoncepcionais e do planejamento familiar, foram entrevistadas 366 mulheres casadas e em idade reprodutiva atendidas nos postos de saúde de Araras. 


\section{Resultados}

A média de filhos entre as heterozigotas AT (média = 2,7647 filhos) não diferiu significativamente da observada entre as suas irmãs AA (média $=2,3778$ filhos), uma vez que a probabilidade obtida pelo teste de Mann-Whitney foi igual a $12,31 \%$. Da mesma forma, a proporção da heterozigotas AT casadas há mais de três anos e sem filhos (três em 68) não diferiu significativamente da observada entre as suas irmãs AA (quatro em 41 ), apresentando o teste exato de Fisher a probabilidade de $43,35 \%$.

Concordando com os resultados observados em relação à talassemia $\beta$, a média de filhos entre as heterozigotas AS (média = 3,0755 filhos) não diferiu significativamente da observada entre as suas irmãs AA (média = três filhos), uma vez que a probabilidade obtida pelo teste de MannWhitney foi igual a $35,24 \%$. Além disso, a proporção de heterozigotas AS casadas há mais de três anos e sem filhos (duas em 51) não diferiu significativamente da observada entre as suas irmãs AA (seis em 37), apresentando o teste exato de Fisher a probabilidade de 13,4\%.

\section{Discussão}

A malária e as hemoglobinopatias não são coincidentes no Brasil. De fato, a Região Amazônica, que concentra a quase totalidade de casos de malária do Brasil $(99,6 \%$, segundo o Ministério da Saúde, 1999), é a que apresenta a menor freqüência de hemoglobinopatias em nosso país $(16,18)$.

Com a erradicação da malária em muitos países com alta prevalência de hemoglobinopatias, a investigação de mecanismos complementares ou alternativos em relação à hipótese de seleção favorável dos heterozigotos por essa parasitemia voltou a ganhar destaque na literatura. Assim sendo, a teoria da fertilidade diferencial das heterozigotas, apoiada pelo estudo indireto de Lisa et al. (12) na Sardenha, merece ser testada em uma população brasileira.

Os resultados do presente trabalho, obtidos em estudo direto de fertilidade e em área não-malarígena, não favoreceram, no entanto, a hipótese de aumento de fertilidade das heterozigotas com o traço talassêmico $\beta$ e com o traço falciforme. É importante ressaltar que a fertilidade das heterozigotas e das suas irmãs-controle foi avaliada por duas variáveis distintas (número médio de filhos e proporção de mulheres casadas sem filhos) e que os testes estatísticos utilizados para a análise de cada uma delas, segundo a sua natureza, foram concordantes.
O uso de grupos controle de irmãs com hemoglobina normal, de mesma distribuição etária das heterozigotas, minimiza a interferência de diversos fatores socioeconômicos e culturais. Assim, por exemplo, não existe nenhuma hipótese plausível de que os grupos das heterozigotas façam maior uso do planejamento familiar e de métodos anticoncepcionais do que os das controles, mascarando a sua eventual maior fertilidade. De fato, além de as heterozigotas AS e AT serem assintomáticas, elas nem sabiam, em sua maioria, que eram portadoras dessas características genéticas quando tiveram os seus filhos. Além disso, o aconselhamento genético de heterozigotas AS e AT, casadas com indivíduos AA, não interfere na decisão de ter ou não filhos, uma vez que estes casais não correm o risco de gerar homozigotos com anemia hemolítica.

Outro aspecto que merece ser enfatizado é o de que a entrevista de 366 mulheres casadas e em idade reprodutiva atendidas nos postos de saúde de Araras revelou que o planejamento familiar é adotado por apenas 30\% dos casais. Como tais casais pertencem ao mesmo nível sociocultural dos componentes da casuística estudada, isto demonstra que o planejamento familiar teve pouca interferência no presente estudo.

Com tal resultado, de todos os mecanismos alternativos propostos no Brasil, apenas a reprodução seletiva das heterozigotas, sugerida por Duchovni-Silva e Ramalho (5, 6), obteve o respaldo da significância estatística. Estes autores testaram a proporção mendeliana na prole de 201 portadores do traço falciforme e de 138 portadores do traço talassêmico $\beta$ casados com cônjuges com hemoglobina normal. Observou-se um excesso de heterozigotos na prole de 107 mães AS (144 AS:89 AA, $X^{2}=12,98$, $p<0,001)$ e de 95 mães AT (117 AT:66 AA, $X^{2}=14,21$, $p<0,001)$ casadas com maridos AA. Já entre os filhos dos pais AS e AT a proporção mendeliana foi respeitada (103 AS:101 AA, $X^{2}=0,019, p=0,89$ e 57 AT:42 AA, $\left.X^{2}=2,27, p=0,13\right)$, demonstrando tratar-se de um efeito exclusivamente materno. É importante ressaltar que tal estudo é isento de distorções de averiguação, uma vez que a análise das famílias foi feita a partir da geração paterna, e não da geração filial (3).

Embora o efeito materno descrito por Duchovni-Silva e Ramalho $(5,6)$ deva contribuir para a manutenção dos polimorfismos da talassemia $\beta$ e da hemoglobina $S$, as altas freqüências destas hemoglobinopatias em nosso país devem ser resultantes, primordialmente, do alto fluxo gênico de populações africanas e européias. 
A importância das hemoglobinopatias em nosso país remonta aos primórdios da nossa história, uma vez que a introdução do gene da hemoglobina $S$ em nossa população teve início por volta de 1530, quando os primeiros negros africanos escravizados chegaram ao Brasil. Como comenta Azevêdo (2), o número total de africanos que aqui chegou é incerto: 3,6 milhões é a cifra mais aceita pelos estudiosos. Com base nesta cifra, é possível estimar que pelo menos 360 mil heterozigotos do gene da hemoglobina $S$ foram incorporados à escassa população do novo país, até então constituída por portugueses e indígenas. Lembre-se de que, da metade do século XVII até fins do século XIX, os negros eram maioria na população brasileira (2).

A partir de 1885, a história das migrações para o Brasil tomou novo rumo com a vinda de outros povos estrangeiros, sobretudo italianos, espanhóis, sírio-libaneses, alemães e japoneses. Desta forma, outra importante hemoglobinopatia hereditária foi introduzida em nosso meio, principalmente pelos maciços contingentes de imigrantes italianos que se estabeleceram no Sul e no Sudeste do Brasil: a talassemia $\beta$. Estes imigrantes procediam de Veneto (Veneza, Pádua, Treviso, Rovigo, Verona), Lombardia (Mântua, Milão) e Emília Romana (Ferrara, Bolonha, Parma, Módena), regiões que são consideradas de alta prevalência da talassemia $\beta$ (16).

A importância primordial do fluxo gênico de populações migrantes, maior do que a da malária, no estabelecimento de altas freqüências de hemoglobinopatias em algumas populações é referida por alguns autores $(12,19)$.

\section{Conclusão}

Os resultados obtidos no presente trabalho não apóiam a hipótese de que o aumento de fertilidade das heterozigotas seja um mecanismo homeostático de manutenção das altas freqüências da hemoglobina $S$ e da talassemia $\beta$ em populações brasileiras.

\section{Referências}

1. Allison, A.C. Protection afforded by sickle cell trait against subter tian malarial infection. British Medical Journal, 1:2904, 1954.

2.Azevedo, E.E. S. Raça: conceito e preconceito. São Paulo: Editora Ática, 1987.

3. Beiguelman, B. Dinâmica dos genes nas famílias e nas populações. Ribeirão Preto: Editora da Sociedade Brasileira de Genética, 1994.

4.C ao,A;Rosatelli, M.C \& Galanello, R.Prevenção e controle das hemoglobino patias. Anais N estlé, 58: 32-41, 1999.

5.D uchovni-Silva, I. \& Ramalho,A.S. Maternal segregation distortion in sickle cell and b-thalassaemia traits? Lancet, 347:691-2, 1996.

6. D uchovni-Silva, I. \& Ramalho A.S. Maternal effect in the sickle cell and $\beta$-thalassemia traits. Genetics and M olecular Biology, 21(suppl. 3): 322, 1998.

7. Eaton,J.W .Malaria and the selection of the sickle gene. In: Embury, S.S.; Hebbel, R.P.; M ohandas, N . \& Steinberg, M.H. (eds.) Sickle cell disease. Basic principles and clinical pratice. $\mathrm{N}$ ova York: Raven Press, 1994. p. 13-8.

8. Flint, J.; Harding, R.M.; Boyce, A J. \& Clegg, J.B.The population genetics of the haemoglobinopathies. Baillieres Clinical H aematology, 6: 215-62, 1993.

9. Friedman, M. J. O xidant damage mediates variant red cell resistance to malaria. N ature, 280:245-50, 1979.

10. Haldane, J.B.S. D isease and evolution. Research Scientific, 19(suppl.): 68-76, 1949
11. Lehman, H .The history of thalassemia. Birth Defects, 18: 1-11, 1982.

12. Lisa, A.; A stolfi, P.; Degio anni, A.; Pasquale, C. D. \& Zei, G. $D$ ifferential fer tility as a mechanism maintaining balanced polymorphism in Sardinia. Human Biology, 66: 683-98, 1994.

13. Ministério da Saúde (MS). Avaliação epidemiológica da malária no Brasil. Brasília: Fundação N acional de Saúde, Ministério da Saúde, 1999.

14. N agel, R.L. \& Roth, E.F. Malaria and red cell genetic defects. Blood, 74: 1213-21, 1989.

15. N aoum, P.C .; Alvarez-Filho, F.; Domingos, C.R. et al. Hemoglobinas anormais no Brasil. Prevalência e distribuição geográfica. Revista Brasileira de Patologia Clínica, 23:6879, 1987.

16. Ramalho, A.S. As hemoglobinopatias hereditárias. Um problema de saúde pública no Brasil. Ribeirão Preto: Editora da Sociedade Brasileira de Genética/C N Pq, 1986.

17. Roth, E.F.; Raventos-Suarez, C.; Rinaldi, A. \& N agel, R.L. Glucose-6-phosphate dehydrogenase deficiency inhibits in vitro growth of Plasmodium falciparum. Proceedings of the National Academy of Sciences U.S.A., 80: 298-305, 1983.

18. Salzano, F.M. \& Tondo, C.V. Hemoglobin types in Brazilian population. Hemoglobin, 6: 85-97, 1982. 
19. Schiliró, G.; Mirabile, E.; Testa, R.; Russo-Mancuso, G. \& $D$ ibenedetto S.P.Presence of hemoglobinopathies in Sicily: a historic perspective. American Journal of M edical Genetics, 69: 200-6, 1997.

20. Teixeira, R.C . \& Ramalho, A.S. Genetics and public health; response of a Brazilian population to an optional hemoglo bino pathy program. Revista Brasileira de Genética, 17: 435-8, 1994.

21. W eatherall, D.J. Los síndromes talasémicos. Barcelona:Toray, 1967.

22. Zei, G.; Lisa, A. \& A stolfi, P. Fertility and malaria in Sardinia. Annals of Human Biology, 17: 315-30, 1990. 